\title{
Usefulness of intraoperative epiaortic echocardiog- raphy to resolve discrepancy between transthoracic and transesophageal measurements of aortic valve gradient - a case report
}

[L'utilité de l'échocardiographie épiaortique peropératoire dans l'élimination des écarts entre les mesures transthoraciques et transasophagiennes du gradient valvulaire aortique - une étude de cas]

Thomas Edrich MD, ${ }^{*}$ Stanton K. Shernan MD, ${ }^{*}$ Brian Smith RDCS, ${ }^{*}$ Holger K. Eltzschig MD*$\dagger$

Purpose: Intraoperative measurement of the aortic valve (AV) gradient in patients undergoing cardiac surgery is routinely performed using transesophageal echocardiography (TEE). In patients with severe aortic stenosis (AS), TEE Doppler beam alignment with the blood flow through the stenotic valve may be inaccurate, resulting in an underestimation of the AV gradient. We describe here the use of epiaortic echocardiography as an alternative to TEE for the intraoperative evaluation of AS.

Clinical features: A patient diagnosed with severe AS (peak pressure gradient by transthoracic echocardiography: $108 \mathrm{mmHg}$ ) was undergoing AV replacement. In contrast, intraoperative TEE examination performed prior to bypass showed only a mild pressure gradient across the $\mathrm{AV}$ (peak pressure gradient: $38 \mathrm{mmHg}$ ). In order to resolve the conflicting information, epiaortic echocardiography was used to measure the AV gradient, confirming severe AS (peak pressure gradient: $98 \mathrm{mmHg}$ ). Most likely, Doppler beam alignment through the stenotic valve was more parallel to blood flow using epiaortic echocardiography, thus revealing the true pressure gradient. Conclusion: Intraoperative epiaortic measurement of AV gradients can be successfully performed in patients where TEE may be inaccurate due to difficulty in aligning a Doppler beam with the transvalvular blood flow.

\begin{abstract}
Objectif : La mesure peropératoire du gradient valvulaire aortique (VA) chez des patients qui subissent une intervention chirurgicale cardiaque est habituellement réalisée par échocardiographie transœsophagienne (ETO). Dans les cas de sténose aortique (SA) sévère, l'alignement du faisceau d'ETO Doppler avec le débit sanguin traversant la valvule sténosée peut être imprécis, ce qui peut entraîner une sous-estimation du gradient VA. L'utilisation de l'échocardiographie épiaortique est décrite, en remplacement de l'ETO dans l'évaluation peropératoire de la SA.
\end{abstract}

Éléments cliniques : Un patient souffrant d'une SA sévère (gradient de pression de pointe maximale par l'échocardiographie transthoracique: $108 \mathrm{mmHg}$ ) devait subir le remplacement d'une VA. Néanmoins, l'ETO peropératoire réalisée avant la greffe a montré seulement un léger gradient de pression de part et d'autre de la VA (gradient de pression de pointe maximale : $38 \mathrm{mmHg}$ ). Pour éliminer les informations contradictoires, nous avons mesuré le gradient VA par échocardiographie épiaortique, ce qui a confirmé une sévère SA (gradient de pression de pointe maximale : $98 \mathrm{mmHg}$ ). L'alignement du faisceau Doppler avec la valve sténosée était, vraisemblablement, davantage parallèle au débit sanguin à l'échocardiographie épiaortique, révélant ainsi le gradient de pression réel.

Conclusion : La mesure épiaortique peropératoire des gradients VA peut être réussie dans les cas où l'ETO est imprécise à cause de difficulté d'alignement du faisceau Doppler avec le débit sanguin transvalvulaire.

From the Department of Anesthesiology, Perioperative and Pain Medicine, ${ }^{*}$ Brigham and Women's Hospital, Harvard Medical School, Boston, Massachusetts, USA; and the Department of Anesthesiology and Intensive Care Medicine, $†$ Eberhard-Karls-University Tübingen, Germany.

Address correspondence to: Dr. Holger K. Eltzschig, Department of Anesthesiology, Perioperative and Pain Medicine, Brigham and

Women's Hospital, Harvard Medical School, 75 Francis Street, Boston, Massachusetts 02115, USA. Phone: 617-732-8218;

Fax: 617-730-9534; E-mail: heltzschig@partners.org

Accepted for publication September 24, 2002.

Revision accepted November 12, 2002. 
I NTRAOPERATIVE epicardial echocardiography was introduced into clinical practice in the early 1970's for the evaluation of open mitral commissurotomy. ${ }^{1}$ Due to the increasing availability and technological development of transesophageal echocardiography (TEE), the use of intraoperative epicardial echocardiography has declined in recent years. Although TEE offers an advantage over epicardial and epiaortic echocardiography by allowing continuous monitoring without interruption of the surgical procedure, TEE probe insertion may be difficult or contraindicated in some patients. ${ }^{2,3}$ In comparison to TEE, epiaortic echocardiography may provide superior imaging for the evaluation of the aortic arch and ascending aortic atherosclerotic disease, cannulation and cross-clamp sites. ${ }^{4,5}$ However the use of epiaortic echocardiography to evaluate aortic valve (AV) stenosis has not been studied in a systematic fashion. We describe a patient with aortic stenosis (AS) undergoing AV replacement, in whom epiaortic echocardiography provided important information that could not be obtained by TEE Doppler examination due to inherent technical limitations.

\section{Case report}

A 51-yr-old patient with symptomatic AS due to calcific degeneration of a bicuspid $\mathrm{AV}$, presented for $\mathrm{AV}$ homograft replacement. Preoperative transthoracic echocardiography (TTE) revealed severe AS (108 $\mathrm{mmHg}$ peak and $73 \mathrm{mmHg}$ mean pressure gradients), moderate aortic regurgitation, left ventricular (LV) hypertrophy, and a LV ejection fraction of $40 \%$. Cardiac catheterization showed absence of obstructive coronary artery disease. However, ventriculography and AV area calculation could not be performed due to difficulty in inserting a guide wire through the stenosed valve, i e., the pressure gradient measured by TTE could not be confirmed.

Intraoperative two-dimensional TEE revealed a severely calcified, bicuspid AV with an approximate area of $0.2 \mathrm{~cm}^{2}$ as measured by TEE planimetry, confirming severe AS. In contrast, the peak trans-AV velocity (3.1 $\mathrm{m} \cdot \mathrm{sec}^{-1}$ ) measured in several views using Doppler echocardiography corresponded to a calculated peak pressure gradient of only $38 \mathrm{mmHg}$ (TEE mean gradient: $21 \mathrm{mmHg}$ ), suggesting mild AS. ${ }^{6}$ In order to resolve the conflict between intraoperative TEE planimetry/preoperative TTE and intraoperative measurement of trans AV pressure gradient with TEE, epiaortic Doppler echocardiography was performed. A $7 \mathrm{MHz}$ probe (V7, Acuson, Mountain View, California, USA) contained within a sterile sheath, was positioned on the anterior ascending aorta permitting the orienta-

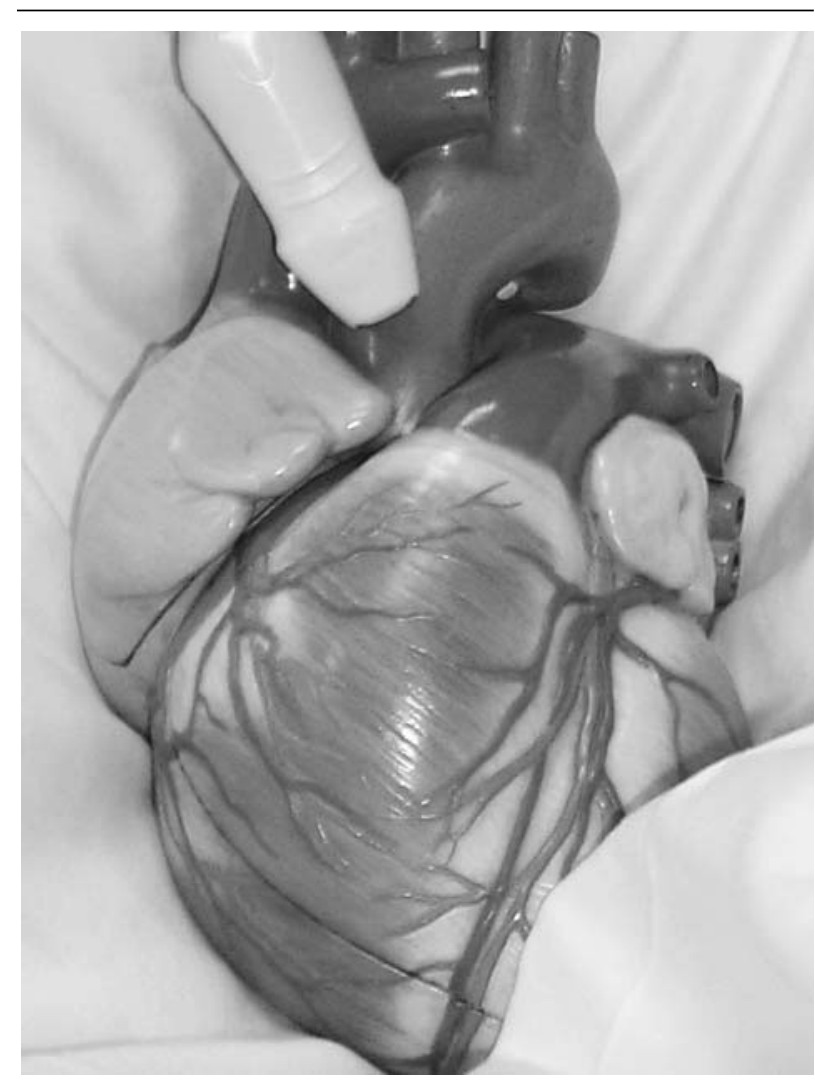

FIGURE 1 Epiaortic echocardiographic probe positioning for aortic valve $(\mathrm{AV})$ interrogation demonstrated on a model of the human heart. The transducer is positioned on the anterior surface of the ascending aorta. The Doppler beam is directed through the AV towards the left ventricular outflow tract to provide optimal alignment with the transvalvular blood flow.

tion of a continuous wave Doppler (CWD) beam through the AV parallel to transvalvular blood flow (Figure 1). A peak gradient of $98 \mathrm{mmHg}$ was obtained, confirming the preoperative TTE findings (Figure 2). The hemodynamic status of the patient remained unchanged throughout the echocardiographic assessment of the AV. After aortotomy, direct inspection of the AV by the surgeon revealed a heavily calcified and fibrotic trileaflet $\mathrm{AV}$, with an estimated area of less than $0.2 \mathrm{~cm}^{2}$, thus confirming the diagnosis of severe AS. The patient underwent an uneventful AV homograft replacement and was subsequently discharged from the hospital on the fourth postoperative day.

\section{Discussion}

Transvalvular pressure gradients can be calculated from Doppler echocardiographic-acquired blood flow veloc- 


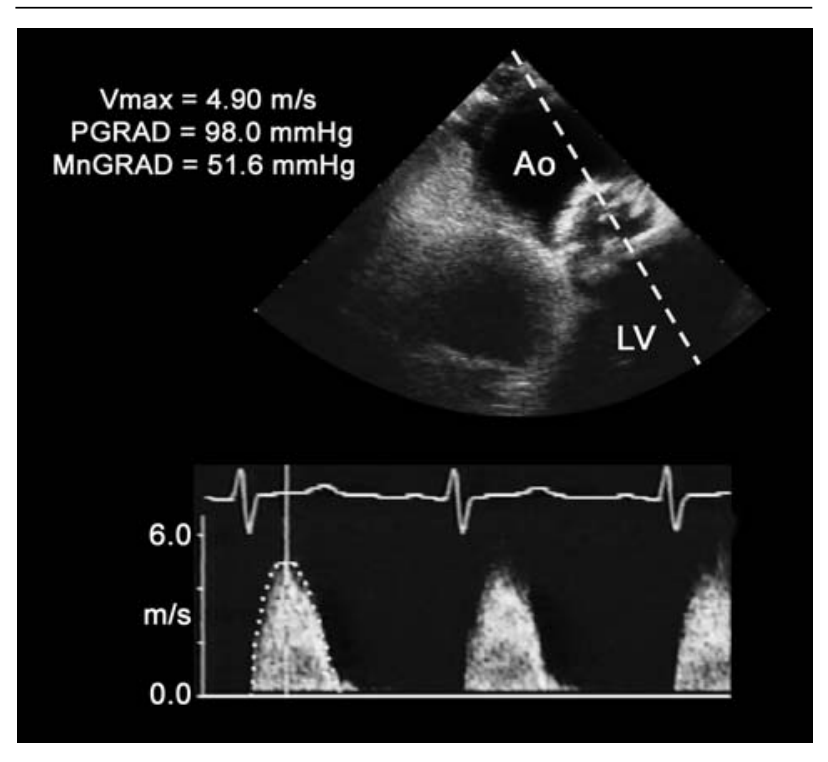

FIGURE 2 Epiaortic echocardiographic assessment of the aortic valve $(\mathrm{AV})$. The upper portion of the image shows the continuouswave Doppler beam oriented through a heavily calcified AV. In this view, alignment of the Doppler beam with transaortic blood flow demonstrated a well-defined Doppler envelope, as shown in the lower portion of the image. The spectral Doppler recording revealed a maximum trans-AV velocity (Vmax) of $4.9 \mathrm{~m} \cdot \mathrm{sec}^{-1} \mathrm{cor}-$ responding to a peak (PGRAD) and mean (MGRAD) pressure gradient of $98 \mathrm{mmHg}$ and $52 \mathrm{mmHg}$, respectively. Ao = ascending aorta; $L V=$ left ventricle.

ity using the modified Bernoulli Equation. However, this calculation assumes parallel alignment of the Doppler beam with the transvalvular blood flow jet to avoid inaccurate measurements. For example, an angle discrepancy of $60^{\circ}$ can result in a $50 \%$ underestimation of blood flow velocity. ${ }^{6}$ In this case report, the transvalvular pressure gradient acquired with TEE Doppler suggested only mild AS. In contrast, both preoperative TTE and intraoperative TEE planimetry convincingly demonstrated severe AS in the setting of a heavily calcified pinhole AV, as could be confirmed via direct inspection by the surgeon after aortotomy. Presumably, the underestimation of AV area by TEE pressure gradient was due to inadequate alignment of the CWD beam with the blood flow velocity jet emerging from the stenotic AV. Difficulty in orienting a TEE Doppler beam through the AV has been previously demonstrated in a study of 79 patients with calcified AS in which adequate alignment was achieved in only $70 \%$ of the cases. A more recent study of 28 mechanically ventilated patients undergoing TEE evaluation of the AV, reported an $11 \%$ failure rate associated with inadequate
Doppler beam alignment due to eccentric jets or the presence of mitral annular calcification that obscured AV visualization. ${ }^{8}$ Epiaortic echocardiography may provide an advantage over TEE by allowing more freedom to maneuver the probe position on the ascending aortic surface, thus facilitating alignment of the CWD beam even in the presence of severe AV stenosis, heavy calcification or eccentric jets.

Although AV planimetry using TEE was possible in the case described, calcification of the AV leaflets can obscure visualization of the orifice area. ${ }^{9}$ Failure of AV planimetry has been demonstrated in over $7 \%$ of patients, especially in the presence of a "pinhole" stenosis. ${ }^{10}$ Furthermore, AV planimetry may not be accurate in patients with heavily calcified valves. ${ }^{11}$ Thus, planimetry may not be a reliable alternative to measurement of an AV pressure gradient via Doppler, either from a transesophageal or an epiaortic transducer position.

The reported case suggests that intraoperative epiaortic Doppler measurement of AS gradients may be successful in patients where TEE is inaccurate due to difficulty in aligning a Doppler beam with the transvalvular blood flow. This may be due to a higher degree of freedom to maneuver the echocardiographic probe from an epiaortic position compared to a transgastric position with TEE.

\section{References}

1 Johnson ML, Holmes JH, Spangler RD, Paton BC. Usefulness of echocardiography in patients undergoing mitral valve surgery. J Thorac Cardiovasc Surg 1972; 64: 922-34.

2 Kallmeyer I, Morse DS, Body SC, Collard CD. Case 22000. Transesophageal echocardiography-associated gastrointestinal trauma. J Cardiothorac Vasc Anesth 2000; 14: 212-6.

3 Kallmeyer IJ, Collard CD, Fox JA, Body SC, Shernan $S K$. The safety of intraoperative transesophageal echocardiography: a case series of 7200 cardiac surgical patients. Anesth Analg 2001; 92: 1126-30.

4 Sylivris S, Calafiore P, Matalanis $G$, et al. The intraoperative assessment of ascending aortic atheroma: epiaortic imaging is superior to both transesophageal echocardiography and direct palpation. J Cardiothorac Vasc Anesth 1997; 11: 704-7.

5 Davila-Roman VG, Phillips KJ, Daily BB, Davila RM, Kouchoukos NT, Barzilai B. Intraoperative transesophageal echocardiography and epiaortic ultrasound for assessment of atherosclerosis of the thoracic aorta. J Am Coll Cardiol 1996; 28: 942-7.

6 Eltzschig HK, Goetz AE, Schroeder TH, Ehlers R, Felbinger $T W$. Transesophageal echocardiography: peri- 
operative evaluation of valvular function (German). Anaesthesist 2002; 51: 81-102.

7 Stoddard MF, Hammons RT, Longaker RA. Doppler transesophageal echocardiographic determination of aortic valve area in adults with aortic stenosis. Am Heart J 1996; 132: 337-42.

8 Blumberg FC, Pfeifer M, Holmer SR, Kromer EP, Riegger GA, Elsmer D. Quantification of aortic stenosis in mechanically ventilated patients using multiplane transesophageal Doppler echocardiography. Chest 1998; 114: 94-7.

9 Tribouilloy C, Shen WF, Peltier M, Mirode A, Rey JL, Lesbre JP. Quantitation of aortic valve area in aortic stenosis with multiplane transesophageal echocardiography: comparison with monoplane transesophageal approach. Am Heart J 1994; 128: 526-32.

10 Hoffmann R, Flachskampf FA, Hanrath P. Planimetry of orifice area in aortic stenosis using multiplane transesophageal echocardiography. J Am Coll Cardiol 1993; 22: 529-34.

11 Cormier B, Iung B, Porte JM, Barbant S, Vahanian A. Value of multiplane transesophageal echocardiography in determining aortic valve area in aortic stenosis. Am J Cardiol 1996; 77: 882-5. 